\title{
Incidence of life-threatening respiratory events after laparoscopic colon surgery with or without continuous respiratory rate monitoring
}

\author{
Hideaki Kawanishi, Junji Egawa*, Satoki Inoue, Takashi Shiota and Masahiko Kawaguchi
}

\begin{abstract}
Background: Respiratory depression (RD) is a critical complication of general anesthesia. The present study investigated the incidence of postoperative life-threatening respiratory events after laparoscopic colon surgery in patients observed using continuous respiratory rate monitoring [RM; with oxygen saturation by pulse oximetry $\left.\left(\mathrm{SpO}_{2}\right)\right]$ and traditional respiratory monitoring ( $\mathrm{TM} ; \mathrm{SpO}_{2}$ monitoring only). In addition, postoperative incidence rates of $\mathrm{RD}$ and desaturation in the RM group were determined.

Findings: In this retrospective observational study, medical records of 214 patients who underwent laparoscopic colon surgery were analyzed. A total of 88 patients with RM were observed and compared with 126 patients with TM. Nineteen patients in the RM group were excluded from the final analyses because of incomplete data. No life-threatening respiratory events were observed in the RM group (0/69), whereas two such events (2/126) occurred in the TM group. Incidence rates of postoperative RD and desaturation within $8 \mathrm{~h}$ after surgery were $17.1 \%(12 / 69)$ and $24.3 \%(17 / 69)$, respectively, in the RM group.

Conclusions: No postoperative life-threatening respiratory events were observed in the RM group. Furthermore, the incidence rates of RD and desaturation were noted to be relatively high.
\end{abstract}

Keywords: Life-threatening respiratory events, Respiratory monitoring, Respiratory depression

\section{Introduction}

Postoperative respiratory depression $(\mathrm{RD})$ is a potentially life-threatening complication of any major surgery. Its etiology of postoperative $\mathrm{RD}$ is multifactorial and includes opioids, residual neuromuscular blocking drugs, anesthetics, and obstructive sleep apnea syndrome (OSAS) [1-5]. In general, laparoscopic colon surgery requires longer anesthesia and surgery times compared with open colectomy [6]. Longer anesthesia time requires higher doses of anesthetics, opioids, and neuromuscular blocking drugs. Surgical technique can also be associated with postoperative RD. The Trendelenburg position and abdominal $\mathrm{CO}_{2}$ gas insufflation during surgery have been found to result in the increased risk

\footnotetext{
* Correspondence: jun.e.m800@gmail.com

Department of Anesthesiology, Nara Medical University, 840 Shijo-cho, Kashihara, Nara 634-8522, Japan
}

of upper airway edema and elevated airway resistance [7]. A previous study revealed that the detection of hypoventilation by pulse oximetry is reliable only in room air breathing conditions [8]. Thus, the Anesthesia Patient Safety Foundation recommends the continuous postoperative monitoring of $\mathrm{SpO}_{2}$ and respiratory rate, particularly when opioids are used for postoperative analgesia [9]. The definition of postoperative RD is not specific and differs among different studies, and this results in the highly variable incidence of RD [10-12]. Although evidence for the incidence of postoperative respiratory depression is inadequate, the risk of severe postoperative $\mathrm{RD}$ may be considerably high in patients undergoing laparoscopic colon surgery. This study compared the incidence rates of postoperative lifethreatening respiratory events after laparoscopic colon surgery in patients monitored using continuous 
respiratory rate and oxygen saturation by pulse oximetry $\left(\mathrm{SpO}_{2}\right)$ [respiratory rate monitoring (RM) group] with those monitored using $\mathrm{SpO}_{2}$ only [traditional respiratory monitoring (TM) group]. In addition, the incidence rates of RD and desaturation within $8 \mathrm{~h}$ after surgery were assessed in the RM group.

\section{Methods}

This retrospective observational study was approved on March 29, 2016, by the Ethics Committee of Nara Medical University Hospital in Kashihara, Japan (study number 1221; principal investigator Junji Egawa).

Medical records of 214 adult patients who underwent laparoscopic colon surgery were assessed. Surgeries were performed by the same surgical team, with the postoperative monitoring of $\mathrm{SpO}_{2}$ and electrocardiogram in all patients. In the $\mathrm{RM}$ group, $\mathrm{SpO}_{2}$ and acoustic $\mathrm{RM}$ sensors were attached after extubation in the operating room. Postoperative respiratory rate could not be monitored in patients who had undergone surgery before June 2012 because of the unavailability of the acoustic RM device (Radical-7 with $\mathrm{RRa}^{\mathrm{Tn}}$, Masimo, Irvine, CA, USA) at our institution. Thus, the RM group included data from June 2012 to January 2014, whereas the TM group included data from January 2010 to April 2012. Incidence rates of postoperative life-threatening events in the RM group $(n=88)$ were compared with those in the TM group $(n=126)$. Lifethreatening respiratory events were defined as those requiring mask ventilation, intubation, or cardiopulmonary resuscitation.

Respiratory rate and $\mathrm{SpO}_{2}$ data, which were collected using the RM device in the RM group, were saved continuously on the server via the SafetyNet ${ }^{\mathrm{Tm}}$ system (Masimo, Irvine, CA, USA). Data were extracted from the server to a dedicated computer after $8 \mathrm{~h}$ of postoperative monitoring. The incidence rate of $\mathrm{RD}$ was defined as a respiratory rate of $<8$ breaths/min for an accumulated time of $>10$ min within $8 \mathrm{~h}$ after extubation. $\mathrm{SpO}_{2}$ value was recorded as the average of $8 \mathrm{~s} \mathrm{SpO}_{2}$ value. Desaturation, defined as an $\mathrm{SpO}_{2}$ of $<90 \%$ within $8 \mathrm{~h}$ after extubation, was assessed for all patients in the RM group. However, $\mathrm{SpO}_{2}$ and $\mathrm{RR}$ in the TM group were manually recorded by caregivers intermittently every $2-3 \mathrm{~h}$ after the surgery. Therefore, these data in the TM group were inadequate for comparison with the RM group.

IBM SPSS Statistics version 24.0 (SPSS Inc., Chicago, IL, USA) was used for all analyses. Dichotomous variables were compared using the chi-square test. Depending on data distribution, results were presented as mean \pm standard deviation or median with interquartile range (IQR). $P$ values of $<0.05$ were considered statistically significant for all analyses.

\section{Results}

Overall, 19 patients in the RM group were excluded from the analysis due to incomplete data. Therefore, 69 patients in the RM group and 126 in the TM group were included in the final analysis. Life-threatening respiratory events were not observed in the RM group (0/69), whereas two such events occurred in the TM group (2/ 126) $(P=0.54)$. Table 1 shows the detailed information for the two cases of life-threatening respiratory events. All demographic variables except for the prevalence of chronic obstructive pulmonary disease (COPD) and smoking were similar between the RM and TM groups (Table 2). The duration of anesthesia and surgery, total amount of remifentanil used, and intraoperative fluid balance were noted to be significantly different between the RM and TM groups (Table 3). Table 4 shows the postoperative data. The total amount of fentanyl used postoperatively was slightly higher in the RM group. Although significant differences were not observed in 28-day mortality rates between the two groups, the median hospital stay was significantly shorter in the RM group ( 8 vs. 10 days, $P<0.01$ ). Incidence rates of RD and desaturation within $8 \mathrm{~h}$ after extubation were $17.3 \%$ $(12 / 69)$ and $24.6 \%(17 / 69)$, respectively.

\section{Discussion}

This retrospective observational study revealed two lifethreatening respiratory events among the 126 patients observed using TM, whereas the 69 patients observed using respiratory rate and $\mathrm{SpO}_{2}$ monitoring did not. The median hospital stay was significantly shorter in the RM than in the TM group ( 8 vs. 10 days, respectively; $P<0.01)$. As expected, the incidence rates of $\mathrm{RD}$ and

Table 1 Details of the two cases of life-threatening respiratory events

\begin{tabular}{|c|c|c|}
\hline Variable & Case 1 & Case 2 \\
\hline Age (year) & 71 & 75 \\
\hline Gender (M/F) & M & M \\
\hline BMI $\left(\mathrm{kg} / \mathrm{m}^{2}\right)$ & 22.44 & 26.82 \\
\hline ASA grade & 2 & 2 \\
\hline Duration of anesthesia (min) & 585 & 778 \\
\hline Anesthetics & Sevoflurane & Sevoflurane \\
\hline Rocuronium (mg) & 230 & 373 \\
\hline Fentanyl $(\mu \mathrm{g})^{\mathrm{a}}$ & 500 & 600 \\
\hline Total fluid balance (mL) & 6630 & 3860 \\
\hline Postoperative analgesia & EPCA & EPCA \\
\hline Assumed causes of RD & Opioid & Opioid and residual NMB \\
\hline Required management & CPR & CPR \\
\hline
\end{tabular}

$B M I$ body mass index, ASA American Society of Anesthesiologists, EPCA epidural patient-controlled analgesia, NMB neuromuscular blockade, $R D$ respiratory depression, $C P R$ cardiopulmonary resuscitation

${ }^{\mathrm{a}}$ Total dose used intraoperatively 
Table 2 Baseline characteristics of study patients

\begin{tabular}{llll}
\hline Variable & $\begin{array}{l}\text { Respiratory rate monitoring } \\
(n=69)\end{array}$ & $\begin{array}{l}\text { Traditional monitoring } \\
(n=126)\end{array}$ & $P$ value \\
\hline Age (year) & $64.8 \pm 12.7$ & $64.3 \pm 13.3$ & 0.818 \\
Gender (M/F) & $39 / 30$ & $69 / 57$ & 0.881 \\
BMI (kg/m $\left.{ }^{2}\right)$ & $22.3 \pm 3.2$ & $22.9 \pm 3.1$ & 0.201 \\
ASA grade & $12 / 53 / 4 / 0$ & $20 / 100 / 6 / 0$ & 0.908 \\
$($ I/IIIII/IV & & $112.6 \pm 14.7$ & 0.052 \\
$\%$ VC & $107.1 \pm 20.3$ & $79.0 \pm 11.1$ & 0.103 \\
FEV1.0\% & $76.3 \pm 10.8$ & $30 / 126$ & 0.006 \\
Smoking & $30 / 69$ & $3 / 126$ & 0.001 \\
COPD & $11 / 69$ & $26 / 126$ & 0.453 \\
$\begin{array}{l}\text { Active liver } \\
\text { disease }\end{array}$ & $11 / 69$ & & 0.457 \\
Hemodialysis & $4 / 69$ & $4 / 126$ &
\end{tabular}

Data are presented as mean \pm standard deviation

$B M I$ body mass index, ASA American Society of Anesthesiologists, \%VC \% vital capacity, FEV1.0\% forced expiratory volume 1.0 (sec) \%, COPD

chronic obstructive pulmonary disease, $D M$ diabetes mellitus

${ }^{a}$ Aspartate aminotransferase $>30$

desaturation were relatively frequent (17.3 and 24.6\%, respectively) within $8 \mathrm{~h}$ after surgery.

Studies have revealed that patients present abnormal vital signs minutes to hours before the emergence of critical adverse events [13]. Specifically, respiratory rate is one of the most important, albeit often neglected, vital signs [14]. According to the American Society of Anesthesiologists, nearly all opioid-related RD events (97\%) were potentially preventable with the utilization of improved monitoring methods [15].

Table $\mathbf{3}$ Intraoperative data of study patients

\begin{tabular}{|c|c|c|c|}
\hline Variable & $\begin{array}{l}\text { Respiratory rate monitoring } \\
(n=69)\end{array}$ & $\begin{array}{l}\text { Traditional monitoring } \\
(n=126)\end{array}$ & $P$ value \\
\hline $\begin{array}{l}\text { Duration of } \\
\text { anesthesia (min) }\end{array}$ & 346 [123-816] & 390 [132-933] & 0.002 \\
\hline $\begin{array}{l}\text { Duration of } \\
\text { surgery (min) }\end{array}$ & 265 [75-719] & 314 [82-856] & 0.001 \\
\hline $\begin{array}{l}\text { Anesthetics } \\
\text { (Sev/Des/Pro) }\end{array}$ & $60 / 2 / 7$ & $113 / 0 / 13$ & 0.158 \\
\hline $\begin{array}{l}\text { Rocuronium } \\
(\mathrm{mg})^{\mathrm{a}}\end{array}$ & 100 [40-235] & 116 [0-745] & 0.091 \\
\hline $\begin{array}{l}\text { Remifentanil } \\
(\mu g)^{a}\end{array}$ & $1668[0-12,730]$ & $885[0-24,691]$ & 0.020 \\
\hline Fentanyl $(\mu \mathrm{g})^{\mathrm{a}}$ & 300 [0-1000] & 300 [0-2150] & 0.966 \\
\hline $\begin{array}{l}\text { Transfusion } \\
(\mathrm{mL})\end{array}$ & 0 [0-280] & 0 [0-3500] & 0.081 \\
\hline Blood loss $(\mathrm{mL})$ & 25 [0-883] & 18 [0-2700] & 0.841 \\
\hline Infusion (mL) & 2200 [200-6250] & 2775 [345-7400] & $<0.001$ \\
\hline Urea $(\mathrm{mL})$ & $329[0-2458]$ & $547[5-3435]$ & $<0.001$ \\
\hline $\begin{array}{l}\text { Total fluid } \\
\text { balance (mL) }\end{array}$ & 1764 [125-4532] & 2122 [30-6630] & 0.001 \\
\hline
\end{tabular}

Data are presented as median [interquartile range]

Sev sevoflurane, Des desflurane, Pro propofol

${ }^{\text {a }}$ Total dose used intraoperatively
Table 4 Postoperative analgesia and outcomes of study patients

\begin{tabular}{llll}
\hline Variable & $\begin{array}{l}\text { Respiratory rate } \\
\text { monitoring }(n=69)\end{array}$ & $\begin{array}{l}\text { Traditional monitoring } \\
(n=126)\end{array}$ & $P$ value \\
\hline EPCA & $29 / 69$ & $104 / 126$ & $<0.001$ \\
IVPCA & $26 / 69$ & $19 / 126$ & 0.001 \\
$\begin{array}{l}\text { Total fentanyl } \\
\text { used }(\mu \mathrm{g})\end{array}$ & $967[0-6942]$ & $836[0-3000]$ & 0.045 \\
$\begin{array}{l}\text { Life-threatening } \\
\text { respiratory events }\end{array}$ & $0 / 69$ & $2 / 126$ & 0.54 \\
$\begin{array}{l}\text { Incidence of RD } \\
\begin{array}{l}\text { Incidence of } \\
\text { desaturation }\end{array}\end{array}$ & $12 / 69$ & Not available & \\
$\begin{array}{l}\text { Mortality } \\
\text { Hospitalization }\end{array}$ & $8 / 69$ & Not available & \\
period & $0 / 69$ & $2 / 126$ & 0.535 \\
\hline EPCA epidura & & $10[3-53]$ & 0.001 \\
\end{tabular}

EPCA epidural patient-controlled analgesia, IVPCA intravenous

patient-controlled analgesia, $R D$ respiratory depression

The Radical-7 with $\mathrm{RRa}^{\mathrm{Ts}}$ enables noninvasive, reproducible, and continuous acoustic respiratory rate and $\mathrm{SpO}_{2}$ monitoring measurements. Mimoz et al. showed that continuous RM using the acoustic device correlated well with capnometry [16]. At our institution, all medical staff have access to patient data including $\mathrm{SpO}_{2}$ and respiratory rate from bedside device screens as well as the central screen at the nurses' stations. Staff can also monitor alarms via smart devices that are connected to the in-hospital network. Neither of the patients with life-threatening respiratory events had preoperative cardiovascular disease. Intraoperative and postoperative electrocardiogram and blood pressure prior to the event were within normal limits. Thus, we suspected that the life-threatening respiratory events were due to RD. Moreover, we suspected that the life-threatening respiratory events were caused by opioid and opioid with residual neuromuscular blockade because of their rapid recovery without any complications and absence of other reasons for these events. In these types of cases, a continuous respiratory monitoring system such as that used in our study would be useful in the early detection of severe respiratory events.

While the amount of total fentanyl used for patientcontrolled anesthesia as well as the rates of COPD and smoking were higher in the RM group, no change in the incidence of life-threatening respiratory events was observed following the implementation of the RM device postoperatively. Several potential reasons could explain this outcome. First, continuous RM may improve the medical staff's awareness of postoperative RD. Indeed, $67 \%$ of nurses who answered the questionnaire after the implementation of the RM system at our institution responded that they paid more attention to potential postoperative RD (data not shown). Second, anesthesiologists may use anesthetic drugs more carefully and observe 
patients more closely after extubation. Finally, medical staff on the wards could identify abnormal respiratory patterns more expeditiously and intervene at earlier stages of RD.

This study has certain limitations. First, this was a retrospective single-center study. Moreover, patient data in the RM group were taken from a different time period than those in the TM group (June 2012-January 2014 vs. January 2010-April 2012); thus, the potential contribution of changes in background variables, such as surgical improvements over time, could not be excluded. In addition, the incidence of life-threatening respiratory events at our institution may be too low to detect statistical significance; a multicenter cohort study with difference-in-difference analysis is necessary to address this concern [17]. Furthermore, this study did not include data on patient intervention by nurses in response to monitor alarms. Moreover, OSAS is one of the major risk factors associated with postoperative RD $[5,18]$. The prevalence of OSAS is estimated to be between 9 and $24 \%$, with approximately $90 \%$ of cases remaining undiagnosed [19]. However, the exact number of patients with OSAS could not be determined in this study. Finally, the duration of anesthesia was longer in the TM than in the RM group (390 vs. 346 min, respectively); however, this difference may not be of clinical significance.

\section{Conclusions}

Life-threatening respiratory events were not observed after laparoscopic colon surgery in patients who underwent continuous $\mathrm{RM}$ with $\mathrm{SpO}_{2}$. The incidence rates of $\mathrm{RD}$ and desaturation were relatively frequent within $8 \mathrm{~h}$ after surgery. The incidence of life-threatening RD events was low at our institution; therefore, multicenter studies are necessary to clarify the efficacy of continuous respiratory monitoring with $\mathrm{SpO}_{2}$.

\footnotetext{
Abbreviations

\%VC: \% vital capacity; ASA: American Society of Anesthesiologists; BMI: Body mass index; COPD: Chronic obstructive pulmonary disease; DM: Diabetes mellitus; EPCA: Epidural patient-controlled analgesia; FEV1.0\%: Forced expiratory volume 1.0 (sec) \%; IVPCA: Intravenous patient-controlled analgesia; OSAS: Obstructive sleep apnea syndrome; RD: Respiratory depression; RM: Respiratory rate monitoring; TM: Traditional respiratory monitoring

Funding

Not applicable.

\section{Authors' contributions}

HK contributed to the study design, study conduct, data analysis, and manuscript preparation. JE contributed to the study design, data interpretation, study conduct, and manuscript preparation. SI contributed to the data interpretation and manuscript review. TS contributed to the data analysis and data interpretation. MK contributed to the study design, data interpretation, and manuscript review. All authors read and approved the final manuscript.
}

\section{Ethics approval and consent to participate}

The Ethics Committee of Nara Medical University Hospital approved this study.

\section{Competing interests}

The authors declare that they have no competing interests.

\section{Publisher's Note}

Springer Nature remains neutral with regard to jurisdictional claims in published maps and institutional affiliations.

Received: 30 June 2017 Accepted: 3 October 2017

Published online: 13 October 2017

\section{References}

1. Dahan A, van den Elsen MJ, Berkenbosch A, DeGoede J, Olievier IC, van Kleef JW, et al. Effects of subanesthetic halothane on the ventilatory responses to hypercapnia and acute hypoxia in healthy volunteers. Anesthesiology. 1994;80:727-38.

2. van den Elsen M, Dahan A, DeGoede J, Berkenbosch A, van Kleef J. Influences of subanesthetic isoflurane on ventilatory control in humans. Anesthesiology. 1995;8:478-90.

3. Berkenbosch A, Teppema LJ, Olievier CN, Dahan A. Influences of morphine on the ventilatory response to isocapnic hypoxia. Anesthesiology. 1997;86:1342-9.

4. Murphy GS, Szokol JW, Avram MJ, Greenberg SB, Shear TD, Vender JS, et al. Residual neuromuscular block in the elderly: incidence and clinical implications. Anesthesiology. 2015;123:1322-36.

5. Kaw R, Michota F, Jaffer A, Ghamande S, Auckley D, Golish J. Unrecognized sleep apnea in the surgical patient: implications for the perioperative setting. Chest. 2006:129:198-205.

6. Clinical outcomes of surgical therapy study group. A comparison of laparoscopically assisted and open colectomy for colon cancer. N Engl J Med. 2004:350:2050-9.

7. Kilic OF, Borgers A, Kohne W, Musch M, Kropfl D, Groeben H. Effects of steep Trendelenburg position for robotic-assisted prostatectomies on intraand extrathoracic airways in patients with or without chronic obstructive pulmonary disease. Br J Anaesth. 2015:114:70-6.

8. Fu ES, Downs JB, Schweiger JW, Miguel RV, Smith RA. Supplemental oxygen impairs detection of hypoventilation by pulse oximetry. Chest. 2004; 126:1552-8.

9. Maddox RR, Williams CK. Clinical experience with capnography monitoring for PCA patients. APSF Newsletter. 2012;26:47-50.

10. Overdyk FJ, Carter R, Maddox RR, Callura J, Herrin AE, Henriquez C. Continuous oximetry/capnometry monitoring reveals frequent desaturation and bradypnea during patient-controlled analgesia. Anesth Analg. 2007;105:412-8.

11. Shapiro A, Zohar E, Zaslansky R, Hoppenstein D, Shabat S, Fredman B. The frequency and timing of respiratory depression in 1524 postoperative patients treated with systemic or neuraxial morphine. J Clin Anesth. 2005;17:537-42

12. Kawanishi $\mathrm{H}$, Inoue $\mathrm{S}$, Kawaguchi M. Impact of absence of critical respiratory rate change on oxygen desaturation following tracheal extubation after general anaesthesia: a propensity score-matched analysis. Anaesthesiol Intensive Ther. 2017:49:181-8.

13. Jones DA, DeVita MA, Bellomo R. Rapid-response teams. N Engl J Med. 2011;365:139-46.

14. Cretikos MA, Bellomo R, Hillman K, Chen J, Finfer S, Flabouris A. Respiratory rate: the neglected vital sign. Med J Aust. 2008;188:657-9.

15. Lee LA, Caplan RA, Stephens LS, Posner KL, Terman GW, Voepel-Lewis T, et al. Postoperative opioid-induced respiratory depression: a closed claims analysis. Anesthesiology. 2015;122:659-65.

16. Mimoz O, Benard T, Gaucher A, Frasca D, Debaene B. Accuracy of respiratory rate monitoring using a non-invasive acoustic method after general anaesthesia. Br J Anaesth. 2012;108:872-5.

17. Dimick JB, Ryan AM. Methods for evaluating changes in health care policy: the difference-in-differences approach. JAMA. 2014;312:2401-2.

18. Vasu TS, Grewal R, Doghramji K. Obstructive sleep apnea syndrome and perioperative complications: a systematic review of the literature. J Clin Sleep Med. 2012;8:199-207.

19. Singh M, Liao P, Kobah S, Wijeysundera DN, Shapiro C, Chung F. Proportion of surgical patients with undiagnosed obstructive sleep apnoea. $\mathrm{Br} J$ Anaesth. 2013;110:629-36. 